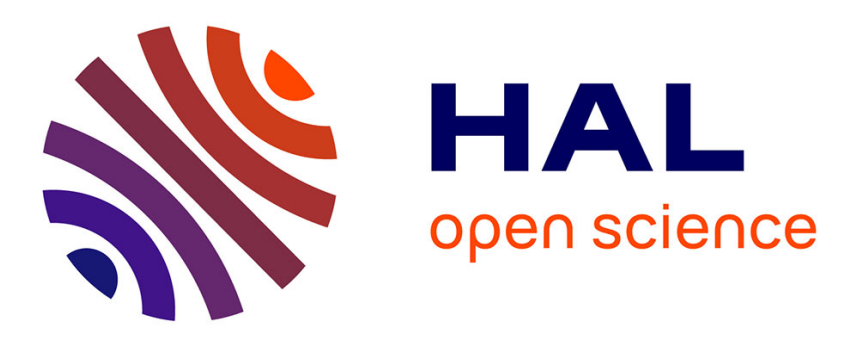

\title{
Crystal defects in dense hydrous magnesium silicate phase A deformed at high pressure: characterization by transmission electron microscopy
}

\author{
Alexandre Mussi, Patrick Cordier, Daniel J. Frost
}

\section{To cite this version:}

Alexandre Mussi, Patrick Cordier, Daniel J. Frost. Crystal defects in dense hydrous magnesium silicate phase A deformed at high pressure: characterization by transmission electron microscopy. European Journal of Mineralogy, 2012, 24, pp.429-438. 10.1127/0935-1221/2011/0024-2126 . hal-02184607

\section{HAL Id: hal-02184607 \\ https://hal.univ-lille.fr/hal-02184607}

Submitted on 16 Jul 2019

HAL is a multi-disciplinary open access archive for the deposit and dissemination of scientific research documents, whether they are published or not. The documents may come from teaching and research institutions in France or abroad, or from public or private research centers.
L'archive ouverte pluridisciplinaire HAL, est destinée au dépôt et à la diffusion de documents scientifiques de niveau recherche, publiés ou non, émanant des établissements d'enseignement et de recherche français ou étrangers, des laboratoires publics ou privés. 


\title{
Crystal defects in dense hydrous magnesium silicate phase A deformed at high pressure: characterization by transmission electron microscopy
}

\author{
Alexandre MUSSI ${ }^{1 \star}$, Patrick CORDIER ${ }^{1,2}$ and Daniel J. FROST ${ }^{2}$ \\ ${ }^{1}$ Unité Matériaux et Transformations, UMR 8207 CNRS-Université Lille1, \\ F-59655 Villeneuve d'Ascq, France \\ ${ }^{2}$ Bayerisches Geoinstitut, Universität Bayreuth, Germany.
}

Cite as:

A. Mussi, P. Cordier \& D.J. Frost (2012) Crystal defects in dense hydrous magnesium silicate phase A deformed at high pressure: characterization by transmission electron microscopy. European Journal of Mineralogy, 24, 429-438, https://doi.org/10.1127/0935-1221/2011/0024-2126

\begin{abstract}
Dense hydrous magnesium silicate (DHMS) Phase A has been deformed at $11 \mathrm{GPa}, 700$ and $400^{\circ} \mathrm{C}$ in the multianvil apparatus. Transmission electron microscopy (TEM) characterizations using the weak-beam dark-field (WBDF) technique, have shown that, at $700^{\circ} \mathrm{C}$, two different types of perfect dislocations are activated with $1 / 3\langle 2 \overline{1} \overline{1} 0\rangle$ and $1 / 3\langle 2 \overline{1} \overline{1} 3\rangle$ Burgers vectors. The $1 / 3\langle 2 \overline{1} \overline{1} 0\rangle$ dislocations glide in the basal plane, but for $1 / 3\langle 2 \overline{1} \overline{1} 3\rangle$ dislocations, no glide plane could be identified. At $400^{\circ} \mathrm{C}$, dissociation of $1 / 3\langle 2 \overline{1} \overline{1} 0\rangle$ dislocations is observed in the basal plane. Furthermore, prismatic and pyramidal glide planes were identified, with dissociations in pyramidal planes, at this temperature. Ultimately, a growth reticular merohedral twin has been observed. The twin law results from a rotation of $180^{\circ}$ around the $[1 \overline{5} 40]$ axis.
\end{abstract}

Keywords: DHMS, phase A, TEM, dislocations, glide plane, twin, dissociation.

"Corresponding author: alexandre.mussi@univ-lille1.fr 


\section{Introduction}

At the surface of the Earth, most activity caused by plate tectonics and mantle convection concentrates at narrow active regions called subduction zones where slabs of oceanic lithosphere sink into the mantle. Subduction zones are also the loci where water, incorporated in ultramafic rocks after hydrothermal alteration, can be injected into the mantle (Schmidt \& Poli, 1998). However, serpentine minerals are not stable beyond $\approx 200 \mathrm{~km}$ depth (Ulmer \& Trommsdorff, 1995) and the question of potential carriers for water into the deep mantle has been raised. In 1967, Ringwood \& Major have shown the existence of some dense hydrous magnesium silicate (DHMS) phases in the $\mathrm{MgO}-\mathrm{SiO}_{2}-\mathrm{H}_{2} \mathrm{O}$ system which can be stable at high pressure. In a subducting slab, phase $A$ is the first post-serpentine phase and the phase $A+$ enstatite assemblage is stable up to $13 \mathrm{GPa}$ (Komabayashi \& Omori, 2006). At mantle transition zone pressure, water is then carried by phase $E$ and superhydrous phase B (Komabayashi \& Omori, 2006).

The importance of these hydrous phases is not restricted to water storage. Phase transitions involving hydrous phases are thought to play a significant role in the generation of intermediate and deep earthquakes (Meade \& Jeanloz, 1991; Yamasaki \& Seno, 2003; Komabayashi et al., 2004; Omori et al., 2004). More recently, the low viscosity of serpentine has been shown to have a strong influence on the dynamics of subduction zones at shallow and intermediate depths by accommodating large deformations (Hilairet et al., 2007, Hilairet \& Reynard, 2009). At greater depths, nothing is known about the rheological properties of hydrous phases. It is the aim of the present study to shed some light on the deformation mechanisms of one of these hydrous phases, phase $A$, starting by the characterization of the crystal defects in this structure.

$\mathrm{Mg}_{7} \mathrm{Si}_{2} \mathrm{O}_{8}(\mathrm{OH})_{6}$ phase $A\left(12\right.$ wt. $\left.\% \mathrm{H}_{2} \mathrm{O}\right)$ is the primary breakdown product of antigorite under the $\mathrm{P}, \mathrm{T}$ conditions of cold slabs (Komabayashi et al., 2005). The structure of phase $A$ is hexagonal, space group $P 6_{3}$, with $a=7.8603 \AA$ and $c=$ $9.5730 \AA$ (Horiuchi et al., 1979). It consists of slightly distorted close-packed layers of oxygen atoms and hydroxyl groups repeating along the $c$ axis in an $A B C B$ sequence (Horiuchi et al., 1979). In this study, iron-free $\mathrm{Mg}_{7} \mathrm{Si}_{2} \mathrm{O}_{8}(\mathrm{OH})_{6}$ phase $A$ has been synthesized and deformed in a multianvil apparatus. Dislocations, slip systems and 
growth twins have been characterized in recovered samples by transmission electron microscopy.

\section{Experimental details}

\section{Synthesis and deformation}

Phase A was synthesized and deformed in the multianvil apparatus at the Bayerisches Geoinstitut in a standard 18/11 assembly. For synthesis, a Pt cylindrical capsule of $12 \mathrm{~mm}^{3}$ ( $2 \mathrm{~mm}$ in diameter and $3.8 \mathrm{~mm}$ long) was filled with a mixture of high purity oxides ( $\mathrm{MgO}, \mathrm{SiO}_{2}$ quartz, brucite) as a starting material. Transformation was achieved at $11 \mathrm{GPa}$ (nominal pressure) and $900^{\circ} \mathrm{C}$ with a heating cycle duration of 240 and 210 min (runs H3006 and S4871). The resulting material is composed of a mixture of phase $\mathrm{A}$ and enstatite, due to an excess in $\mathrm{MgO}$. The recovered samples were end-polished and placed in a second high-pressure assembly designed to induce deviatoric stresses during compression (Cordier \& Rubie, 2001). In this assembly, the specimen is placed between two alumina pistons. The deformation experiments were run at $11 \mathrm{GPa}$ and $700^{\circ} \mathrm{C}$ for a duration of $45 \mathrm{~min}$ (run $\mathrm{H} 3008$ ) and $400^{\circ} \mathrm{C}$ for a duration of $60 \mathrm{~min}$ (run S4873).

\section{Transmission Electron Microscopy}

The specimens recovered after deformation were cut into two halves from which two TEM foils were prepared by mechanical polishing to a thickness of $20 \mu \mathrm{m}$. Since phase $A$ is very sensitive to irradiation, electron transparency was reached by ion milling (in a Gatan ${ }^{\circledR}$ DuoMill ${ }^{\mathrm{TM}}$ Model 600 ) at liquid nitrogen temperature in order to minimize damage. $\mathrm{A} 15^{\circ}$ incident ion beam and $4.5 \mathrm{kV}$ accelerating voltage were used for the ion sputtering conditions. A thin carbon film was finally deposited on the thin foils.

The specimens were characterized at the TEM facility of the University of Lille. A Philips ${ }^{\circledR}$ CM30 microscope operated at $300 \mathrm{kV}$ was used. As already mentioned, phase $A$ is extremely sensitive to beam damage. TEM characterization could only be performed under conditions adjusted to slow down beam damage. We used a small condenser aperture $(100 \mu \mathrm{m})$, a small spot size $(300 \mathrm{~nm})$, a low magnification $(\mathrm{M}=$ $3900 \times)$ and a Gatan $^{\circledR}$ cold stage operated with liquid nitrogen $\left(T \approx-160^{\circ} \mathrm{C}\right.$ near the thin foil). 
Weak-beam dark-field (WBDF) characterizations were conducted using the conventional invisibility criterion $\boldsymbol{g} \cdot \boldsymbol{b}=0$ and with the thickness-fringe method (Ishida et al., 1980, Miyajima \& Walte, 2009). This latter technique gives the $\boldsymbol{g} \cdot \boldsymbol{b}$ product by counting the number and the orientation of thickness fringes terminating on the studied dislocation. The thickness-fringe method has the following advantages:

- Three independent $\boldsymbol{g} \cdot \boldsymbol{b}$ conditions are necessary to obtain the Burgers vector without compulsory extinction conditions.

- The extinction conditions $(\boldsymbol{g} \cdot \boldsymbol{b}=0)$ are sometimes affected by residual contrasts (edge components, anisotropic crystals, etc). This is not the case for the thickness fringe method.

Precession electron diffraction (Vincent \& Midgley, 1994) was performed with a "Spinning Star" precession module from the Nanomegas company. This technique allows easy identification of phases and selection of high structure factor reflections for dislocation imaging and characterization.

Dislocation densities have been estimated using the method of Ham (1961) based on the superimposition of a periodic square network onto the TEM images. Counting the number of intersections between the dislocation lines and the network allows estimating the local dislocation density $\rho$ using the relation:

$\rho=\frac{2 n}{L . t}$

where $n$ is the number of intersections, $L$ is the total length of the network lines and $t$ is the average thickness of the foil in the observed area. The thickness has been estimated by the Electron Energy Loss Spectroscopy (EELS) thickness map method (Meltzman et al., 2009).

\section{Results}

\section{Dislocation Burgers vectors and slip planes in phase $A$, deformed at $700^{\circ} \mathrm{C}$}

Dislocations are observed in most of the grains of phase $A$; only the smallest ones (i.e. below $2 \mu \mathrm{m}$ ) appear to be free from dislocations. The average grain size is approximately $50 \pm 10 \mu \mathrm{m}$ and the dislocation densities in all these grains are more or less equivalent (approximately $10^{13} \mathrm{~m}^{-2}$ as measured with the Ham method (1961)). Twelve grains have been characterized in detail in the present study. Generally, dislocations are entangled; only few isolated dislocations have been 
noticed, which complicates their analyses. Some sub-grain boundaries have been seen, but their occurrence is not pervasive (Figure 1).

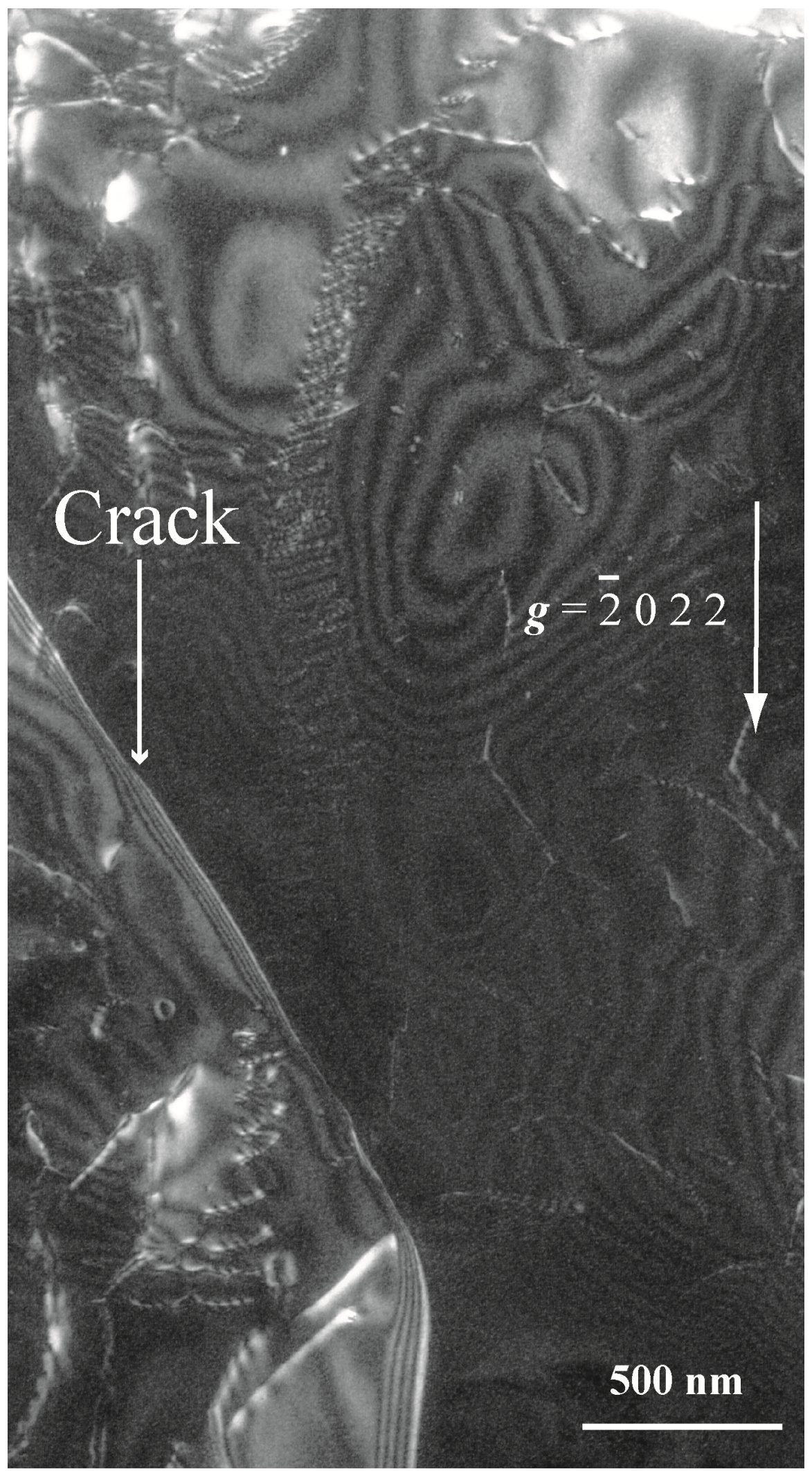

Figure 1: WBDF images obtained along the $[11 \overline{2} 3]$ zone axis, with $\mathbf{g}: \overline{2} 022$, showing a sub-grain boundary crossed by a crack. 
The nature of the dislocations has been investigated using WBDF technique. Figure 2 illustrates the characterization of six dislocations observed close to the $[\overline{1} 100]$ zone axis. They are in contrast with the $\overline{1} \overline{1} 2 \overline{1}$ diffraction vector (see figure 2a) and out of contrast with 0002 (see Figure 2b). They are $1 / 3\langle 2 \overline{1} \overline{1} 0\rangle$ (also called $<a>$ ) dislocations. Figure 3 shows the characterization of two dislocation families belonging to a sub-grain. The first dislocation family is in contrast while the second one is out of contrast (figure 3a), with a diffraction vector 0004 . Conversely, the second dislocation family is in contrast while the first one is out of contrast (figure $3 b)$, with $0 \overline{2} 2 \overline{2}$. These dislocations are perfect ones and can only be $\pm 1 / 3[1 \overline{2} 13]$ or \pm $1 / 3[11 \overline{2} \overline{3}]$, that is to say $\langle c+a\rangle$ dislocations, for the first family, and $\pm 1 / 3[\overline{1} 2 \overline{1} 0]$ or \pm $1 / 3[11 \overline{2} 0]$, i.e. $\langle a\rangle$ dislocations, for the second family. It is worth noticing that no [0001] dislocation $(\langle c\rangle)$ has been identified among all the analysed dislocations, but their occurrence cannot be excluded.
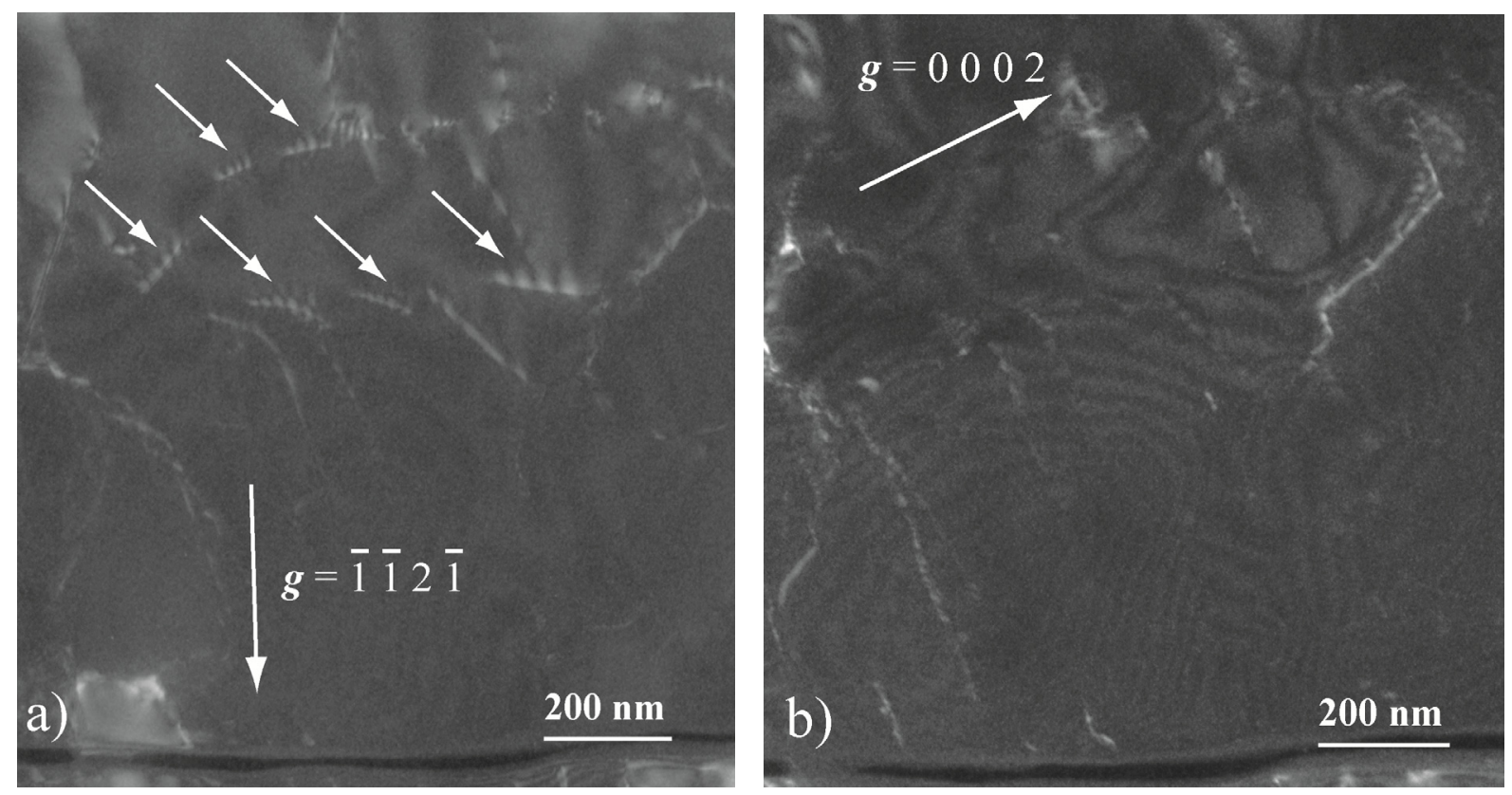

Figure 2: Micrographs in WBDF conditions viewed along the $[\overline{1} 100]$ zone axis. (a) Condition g: $\overline{1} \overline{1} 2 \overline{1}$, the six $1 / 3\langle 2 \overline{1} \overline{1} 0\rangle$ dislocations (indicated by the arrows) are in contrast; (b) condition $\mathbf{g}$ : 0002 , the six $1 / 3\langle 2 \overline{1} \overline{1} 0\rangle$ dislocations are out of contrast. 

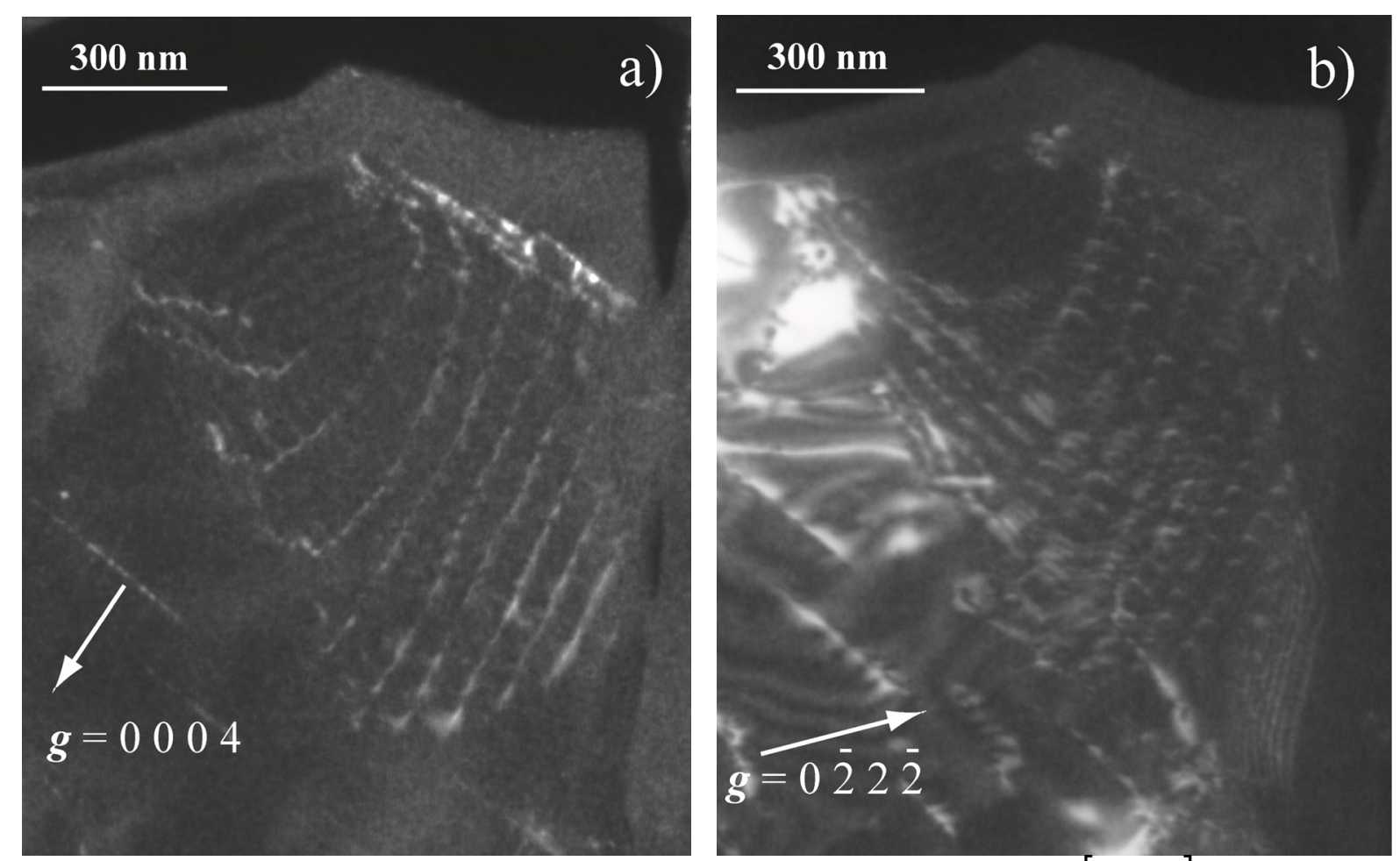

Figure 3: Micrographs of a sub-grain, in WBDF condition, viewed along the $[2 \overline{1} \overline{1} 0]$ zone axis, (a) with g: 0004 and (b) $\mathbf{g}: 0 \overline{2} 2 \overline{2}$. The Burgers vector of the dislocation family in contrast with $\mathbf{g}$ : 0004 , is of the $\langle c+a\rangle$ type. The Burgers vector of the dislocation family in contrast with $\mathbf{g}: 0 \overline{2} 2 \overline{2}$, is of the $\langle a\rangle$ type.

We have also performed slip planes characterizations. Figure 4 shows several dislocation segments which appear straight and aligned along a direction which can be interpreted as the trace of their glide plane. These dislocations are thus lying in the (0001) plane. They are in contrast with the $11 \overline{2} \overline{1}$ diffraction vector, and out of contrast with 0004 showing that they are $\langle a\rangle$ dislocations gliding in (0001). 


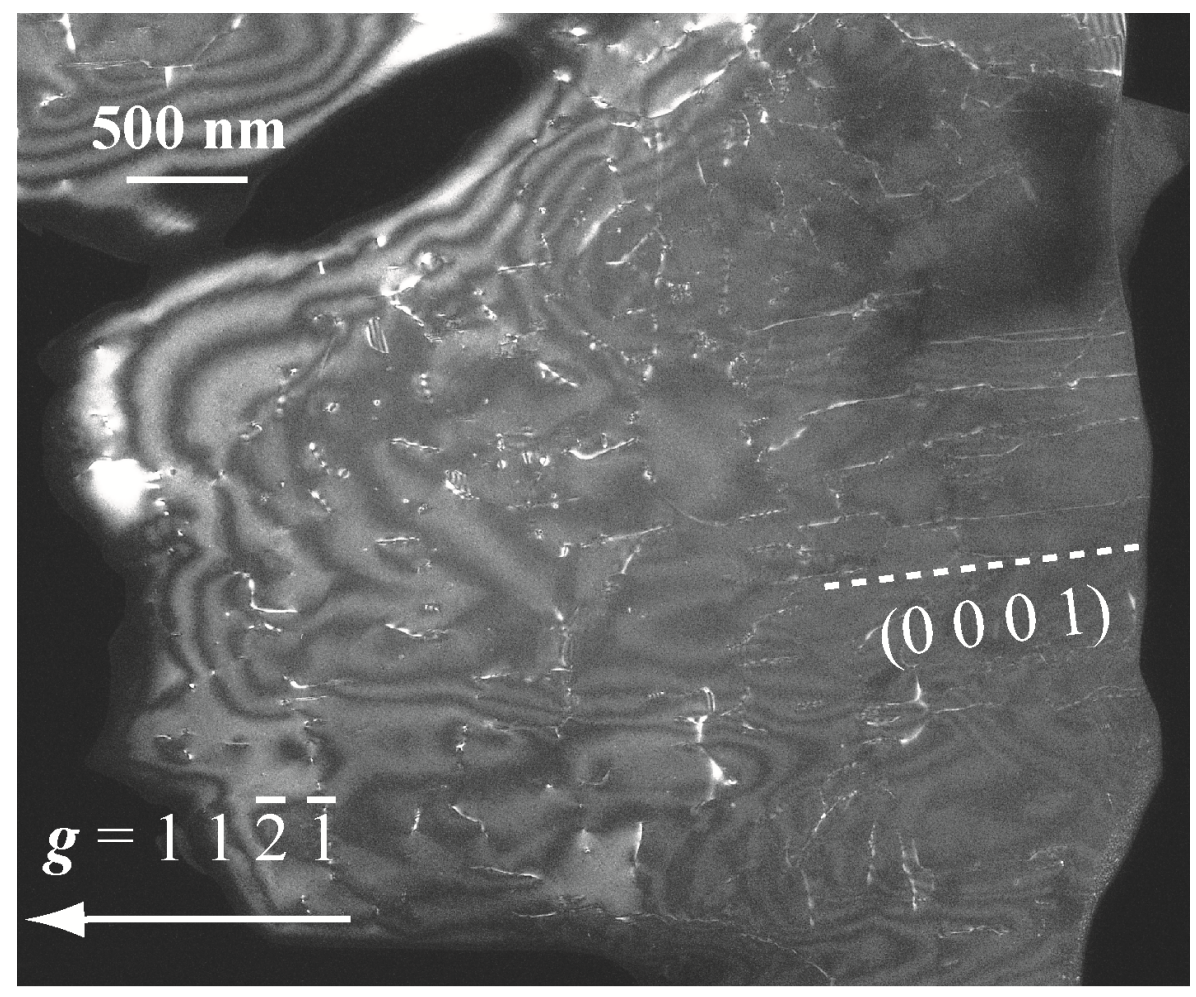

Figure 4: WBDF picture obtained with $\mathbf{g}: 11 \overline{2} \overline{1}$, viewed along the $[\overline{1} 100]$ zone axis, showing several $\langle a\rangle$ dislocations lying in the (0001) plane.

\section{Dislocation Burgers vectors and slip planes in phase $A$ deformed at $400^{\circ} \mathrm{C}$}

The specimen microstructure is composed of small grains of $8 \pm 2 \mu \mathrm{m}$. All the analyzed grains (47 grains) contain lots of dislocations. Very few sub-grain boundaries were noted and the average dislocation density is $\rho \approx 2.10^{13} \mathrm{~m}^{-2}$.

The specimen of phase $\mathrm{A}$, deformed at $400^{\circ} \mathrm{C}$, contains a lot of evidences for dissociated dislocations. Figure 5 shows dissociation in the basal plane. On Figure 5a $(\boldsymbol{g}: 0 \overline{2} 2 \overline{2})$, one partial dislocation (labelled 1 ) is out of contrast. The second partial dislocation (labelled 2) and the stacking fault (separation of the order of $1 \mu \mathrm{m}$ ) are in contrast. On figure $5 b$, the plane containing the faults and the dislocations is seen edge-on. Figure $5 \mathrm{a}$ shows that every third stacking faults are out of contrast when stacking faults are superimposed. Consequently, the g.b product is $n / 3$. Thus, the partial dislocation 1 can only be $\pm 1 / 3[01 \overline{1} 0]$, and the associated partial dislocation 2 is $\pm 1 / 3[10 \overline{1} 0]$ or $\pm \frac{1}{3}[1 \overline{1} 00]$. Consequently, the dissociation law is:

$1 / 3[01 \overline{1} 0]+1 / 3[10 \overline{1} 0] \Leftrightarrow 1 / 3[11 \overline{2} 0]$ or $1 / 3[01 \overline{1} 0]+1 / 3[\overline{1} 100] \Leftrightarrow 1 / 3[\overline{1} 2 \overline{1} 0]$. 

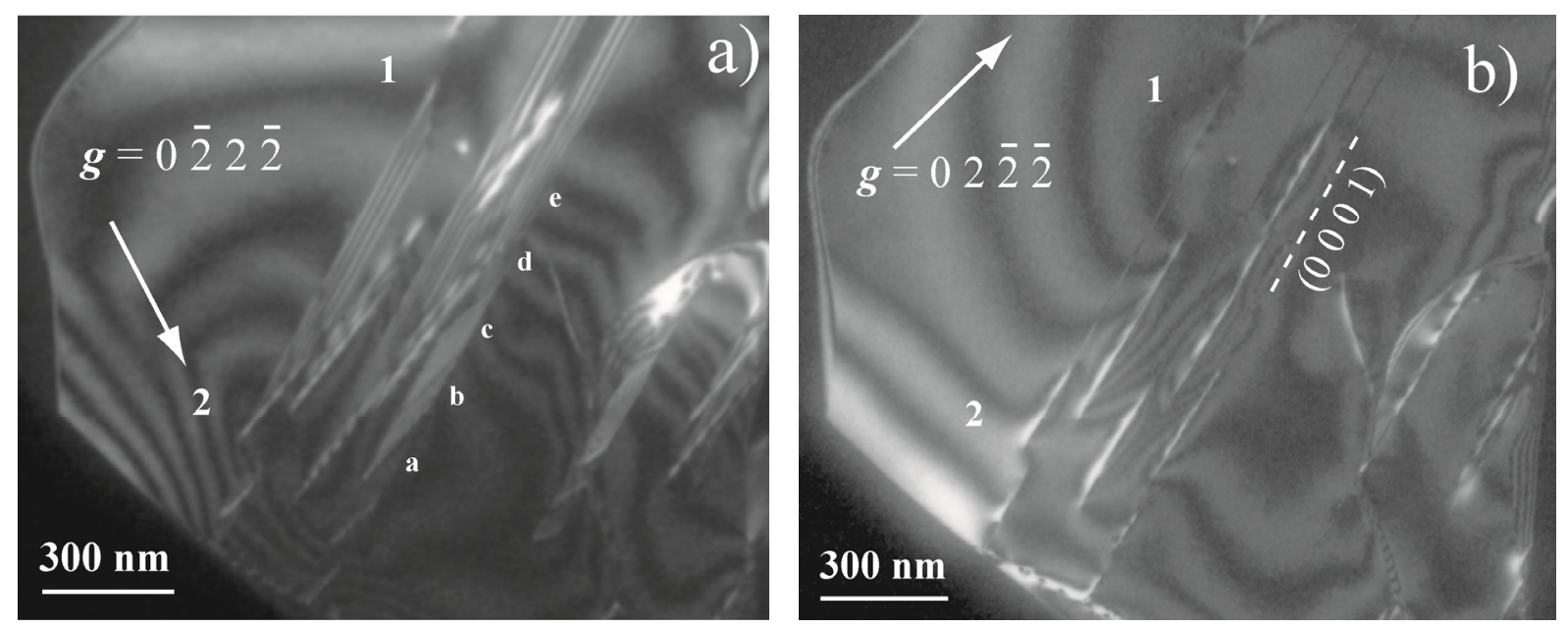

Figure 5: WBDF micrographs of dissociated dislocations in the basal plane, viewed along the

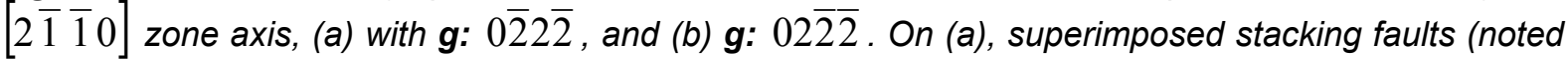
$a, b, c, d$ and e). "a" and "d" are out of contrast.

Furthermore, Figure 6a shows evidence for both perfect and dissociated $\langle a\rangle$ dislocations which glide on the basal plane. With $\boldsymbol{g}: 41 \overline{5} 0$, the thickness-fringe method shows that the $\boldsymbol{g} \cdot \boldsymbol{b}$ product is \pm 2 for the dislocation labelled 3 which is compatible with the Burgers vector of a partial dislocation: $\pm 1 / 3[01 \overline{1} 0]$. Moreover, with the same diffraction vector and next to the previous dislocation, the thicknessfringe method shows a dislocation (labelled 4) with a g.b product of \pm 5 . This corresponds to a perfect $\pm 1 / 3[11 \overline{2} 0]$ dislocation.

We found in the specimen deformed at $400^{\circ} \mathrm{C}$ evidences for prismatic and pyramidal glide. Figure $6 \mathrm{~b}$ shows evidences for glide in $(1 \overline{2} 10)$ and $(\overline{2} 110)$ (seen edge on). Similarly, figure $7 a$ shows pyramidal planes $(11 \overline{2} 1)$ and $(11 \overline{2} \overline{1})$ edge-on containing evidences of glide. In the same area (Figure 7b), we found dislocations with dissociation out of the basal plane. The angle between the stacking fault and the basal plane suggest that dissociation occurs in a pyramidal plane. This defect must be related to $1 / 3\langle 2 \overline{1} \overline{1} 3\rangle$ glide. Several observations show that the two related partial dislocations exhibit the same contrast suggesting a symmetrical dissociation law, possibly: $1 / 6\langle 2 \overline{1} \overline{1} \overline{3}\rangle+1 / 6\langle 2 \overline{1} \overline{1} \overline{3}\rangle \Leftrightarrow 1 / 3\langle 2 \overline{1} \overline{1} \overline{3}\rangle$. 

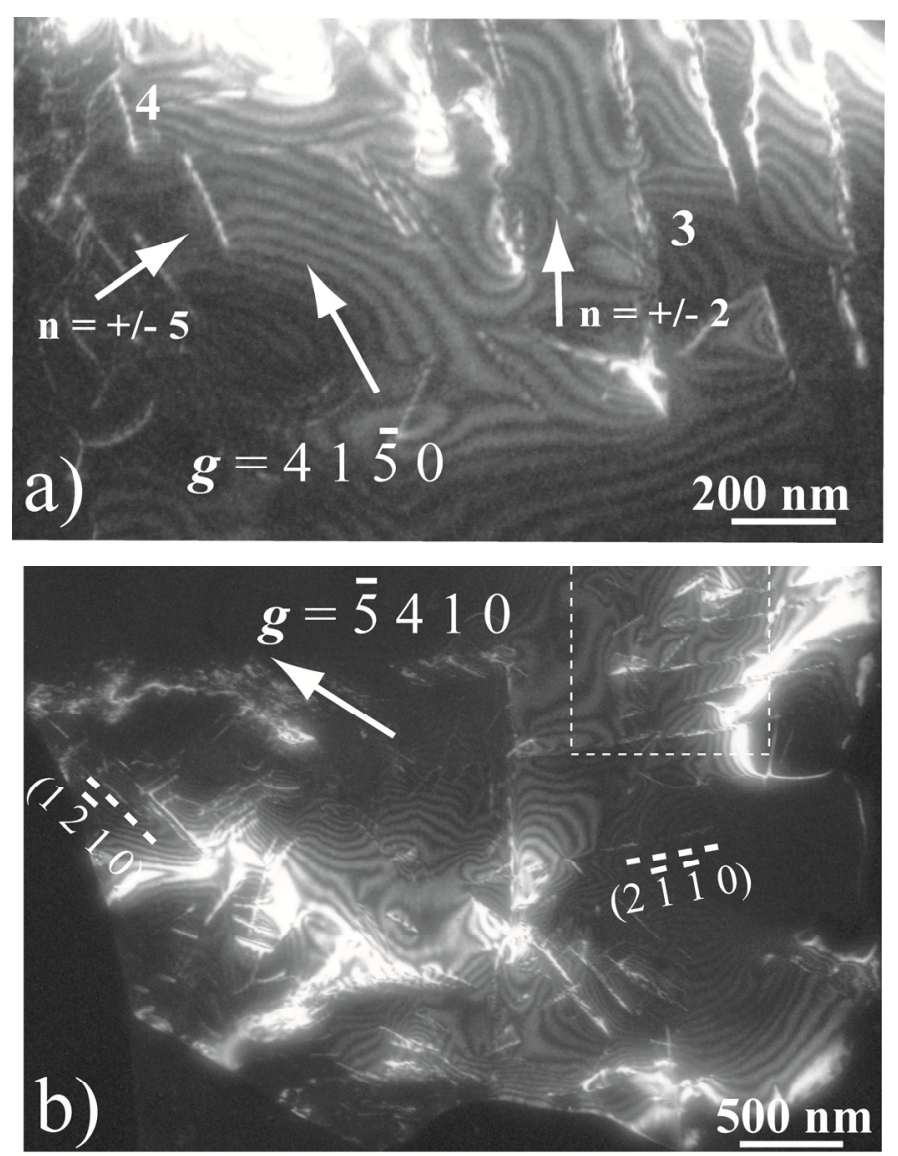

Figure 6: (a) Micrograph (close to [0001] zone axis and with $\boldsymbol{g}$ : $41 \overline{5} 0$ ), with $\pm 1 / 3[11 \overline{2} 0]$ and $\pm 1 / 3[01 \overline{1} 0]$ dislocations showing fringe contrast characteristic of $\mathbf{g} \cdot \boldsymbol{b}$ products \pm 5 and \pm 2 respectively; (b) The dashed rectangle indicates the area magnified in (a): (1 $\overline{2} 10)$ and $(2 \overline{1} \overline{1} 0)$ glide planes are highlighted (dashed white straight lines), with $\mathbf{g}: \overline{5} 410$.
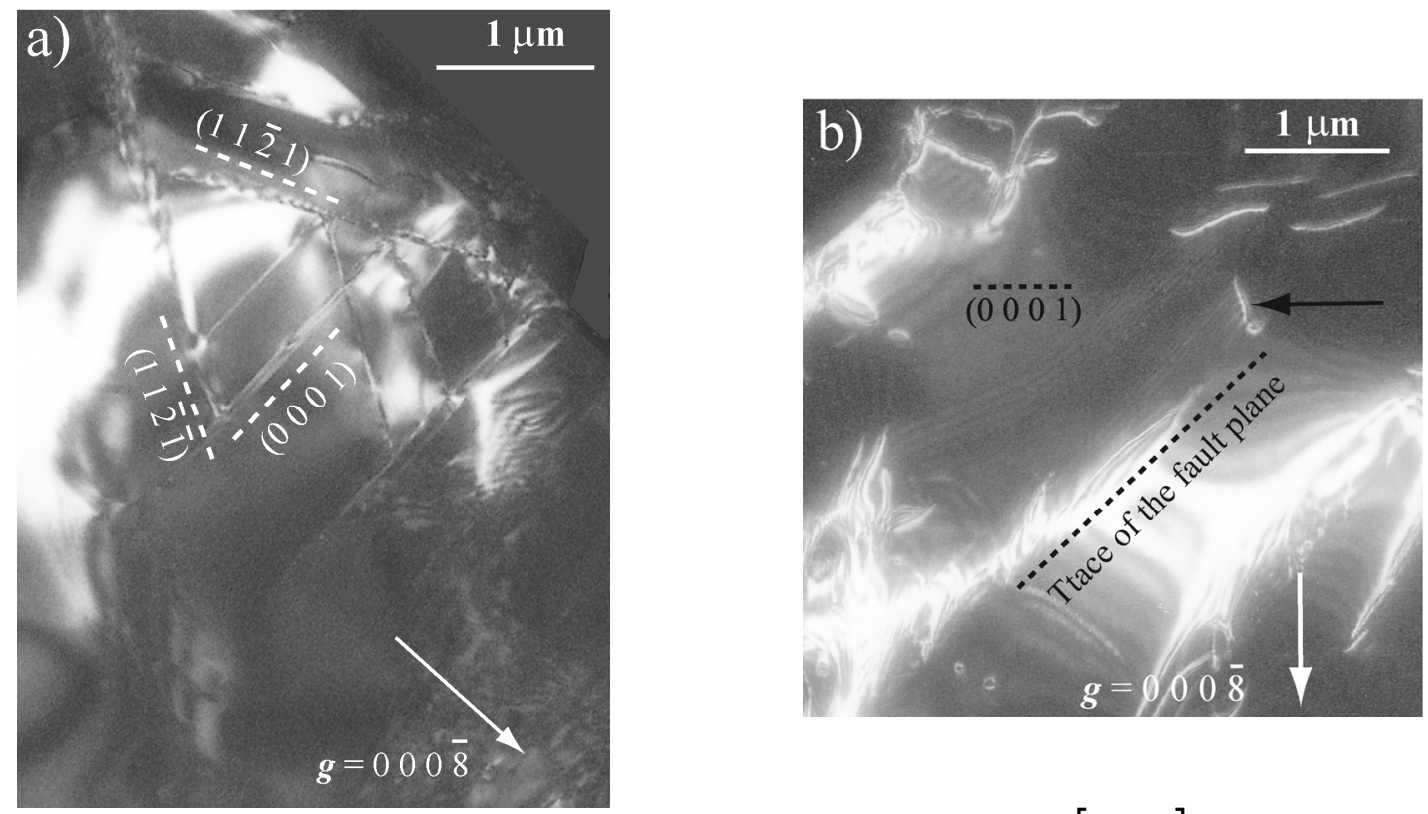

Figure 7: Micrographs in WBDF conditions with $\mathbf{g}: 000 \overline{8}$, along the $[1 \overline{1} 00]$ zone axis. (a) The (0001), $(11 \overline{2} 1)$ and $(11 \overline{2} \overline{1})$ planes are edge one (dashed white straight lines); (b) highly dissociated dislocations in a pyramidal plane are indicated by a black arrow. 


\section{Twinning}

In addition to these slip systems, we have found some evidence for twinning in phase A. Figures $8 \mathrm{a}$ and $8 \mathrm{~b}$ show a straight boundary parallel to (0001) which separates two domains with markedly different orientations as shown by their diffraction contrasts. The micrograph has been obtained near the $[2 \overline{1} \overline{1} 0]$ zone axis. However, when a WBDF image is formed with the 0004 diffraction vector, the boundary vanishes and the diffraction contrast appears perfectly continuous across the boundary (figure $8 \mathrm{c}$ ). Both sides of this boundary share the same [0001] direction, either positive or negative, suggesting a twinning relationship. Here, the twin plane is (0001). We have performed selected area precession electron diffraction on both sides of the twin boundary seen on figure 8 . A symmetry relationship is clearly visible on these diffraction patterns (Figure 10), confirming twinning.

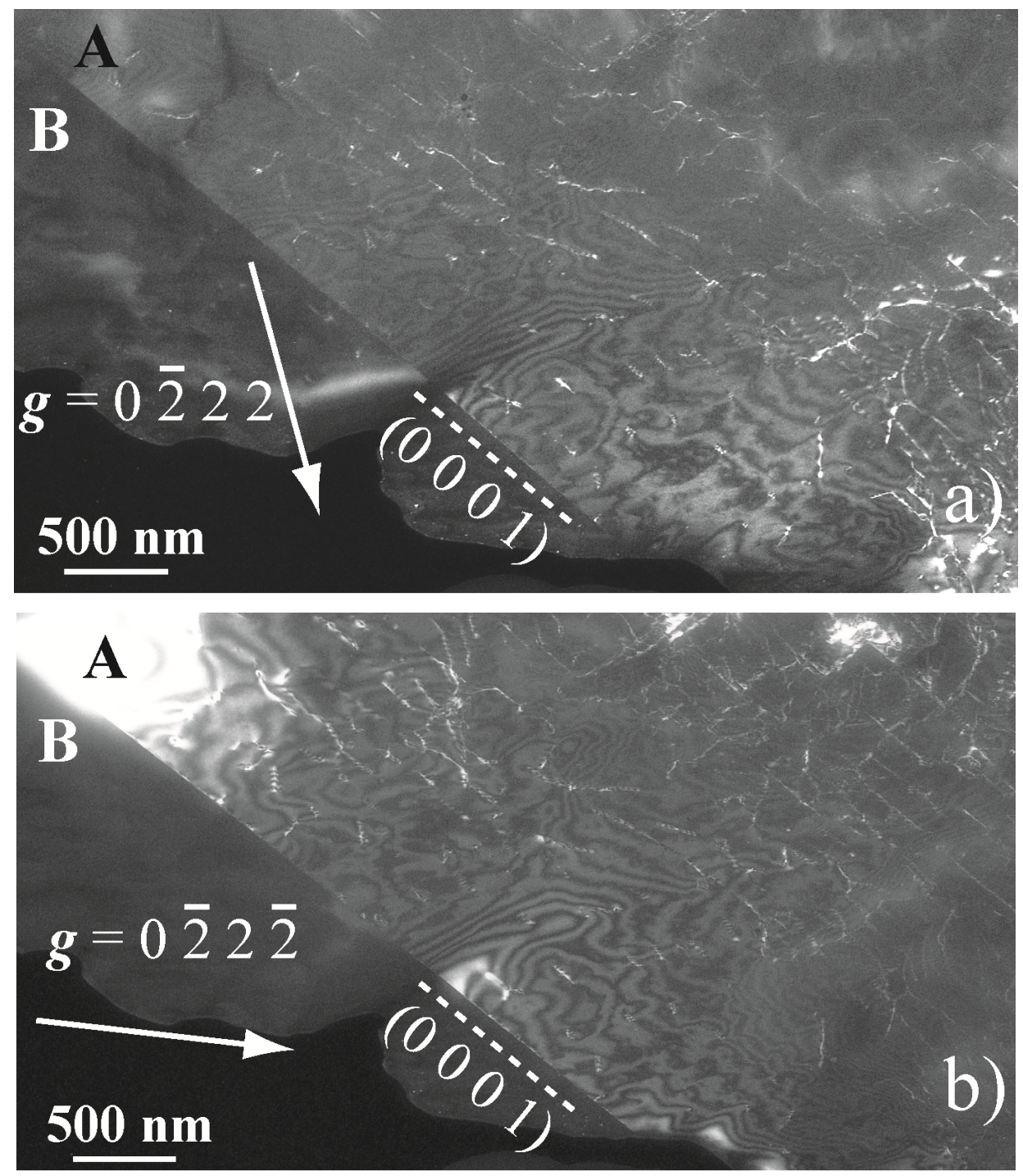




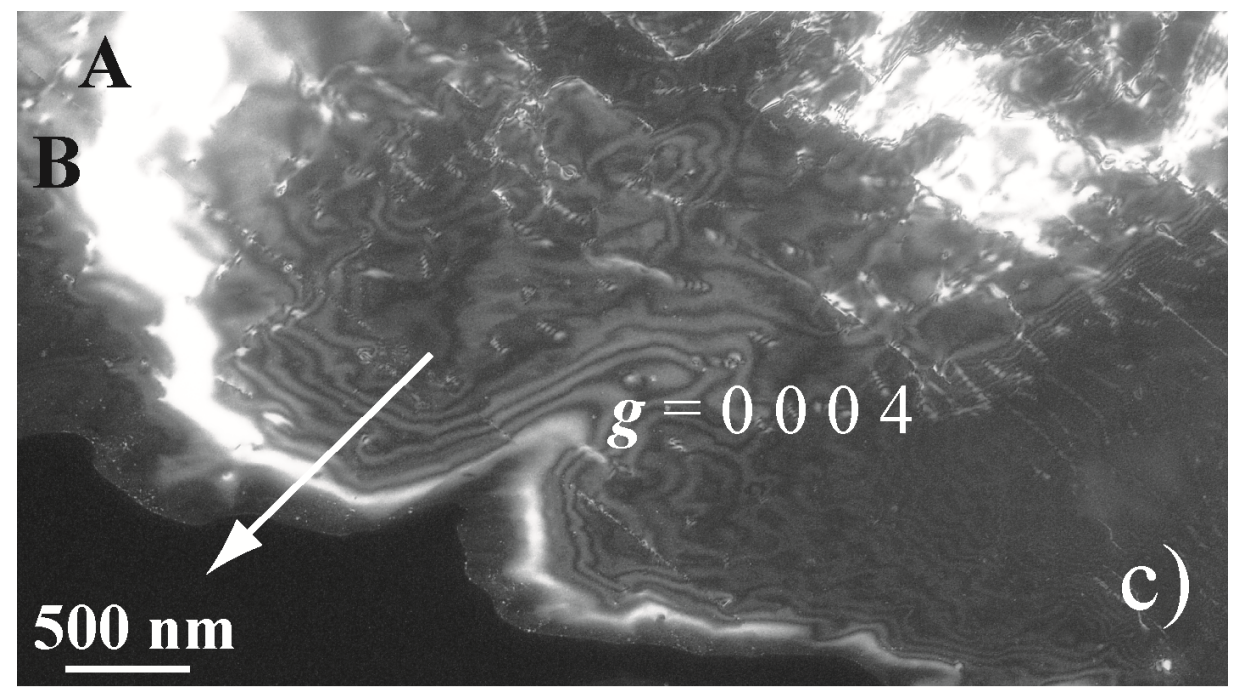

Figure 8: WBDF images obtained along the $[2 \overline{1} \overline{1} 0]$ zone axis, (a) with $\boldsymbol{g}: 0 \overline{2} 2 \overline{2}$, (b) $\boldsymbol{g}: 0 \overline{2} 22$ and (c) g: 0004 . A twin, along the (0001) plan, is noticeable. The [0004] direction seems to be invariant; otherwise the $[0004]$ direction is changed into the $[000 \overline{4}]$ direction.

\section{Discussion}

Plastic deformation experiments in the multianvil apparatus represent complex tests as discussed by Cordier \& Rubie (2001) and Thurel \& Cordier (2003). Large, non-hydrostatic, stresses are applied during cold compression. When the specimen is heated, and if temperature is high enough, plasticity is induced by relaxation. Recovery of cold deformation (if present) starts and new dislocation sources can operate. After a given time, stresses are relaxed, plastic deformation stops, but recovery processes can still be active if temperature is high enough. These experiments are poorly adapted to quantitative rheological studies, however, they represent a very efficient way to introduce dislocations. Since strains are small, and since recovery can be enhanced (depending on temperature and time duration), the dislocation densities are usually well adapted for TEM characterization of dislocation Burgers vectors and slip plane. This is the case in the present study where the sample, made of a mixture of phase $A$ and enstatite, shows pervasive evidence of dislocation activity with a dislocation density of the order of $10^{13} \mathrm{~m}^{-2}$.

Dislocations are very energetic defects. The elastic energy stored in the crystal surrounding the dislocation line roughly scales as $\mu \mathrm{b}^{2}$ where $\mu$ is the shear modulus and $b$ the modulus of the Burgers vector. For this reason, dislocation Burgers vectors are usually in the direction of the smallest lattice repeats of the unit cell. Phase $A$ is hexagonal with a c/a ratio of 1.22 . The modulus of the Burgers 
vectors of $\langle a\rangle$ dislocations (the smallest lattice dimension) is already quite large: 7.86 $\AA$. Perfect $\langle a\rangle$ dislocations represent an important fraction of the observed defects establishing their role in the plasticity of phase A. We did not find any evidence for $\langle c\rangle$ dislocations. Although it is difficult to definitely rule out the possibility of $\langle c\rangle$ glide. Alternatively, we have found pervasive evidence for activation of $\langle c+a\rangle$ dislocations. Their Burgers vector's length is $12.39 \AA$, corresponding to an elastic energy 2.5 times larger than that of $\langle a\rangle$ dislocations. Such large Burgers vectors are unusual in materials science (with the exception of recently discovered complex metallic alloys (Heggen et al., 2010)) but there exist other cases in mineral physics, in olivine, wadsleyite or garnets for instance. In olivine, the absence of [010] dislocations has been generally attributed to the magnitude of its Burgers vector $(10.2 \AA)$. Generalized stacking fault calculations have shown recently, however, that the absence of [010] dislocations is due in fact to the difficulty of shearing the olivine structure along this direction (Durinck et al., 2005). In wadsleyite, [010] dislocations exhibit very large Burgers vectors $(11.44 \AA)$, however, the core energy is relaxed by complex dissociation schemes (Thurel \& Cordier, 2003, Metsue et al., 2010). Garnets, for which the Burgers vectors of $1 / 2<111>$ dislocations is ca. $10 \AA$ is more comparable to phase $A$ deformed at $700^{\circ} \mathrm{C}$, since in both cases WBDF shows no visible dissociation. Given the resolution of WBDF, this means that if some core spreading exists, it must be less than $15 \mathrm{~nm}$ wide.

However, dissociated dislocations in basal and pyramidal planes are present in the specimen deformed at $400^{\circ} \mathrm{C}$. These partial dislocations result from the dissociation of $\langle a\rangle$ and $\langle c+a\rangle$ dislocations, respectively.

This leads us to the issue of slip planes. The crystal structure of phase A differs strongly from those of phyllosilicates which carry water at lower pressures. It consists of slightly distorted close-packed layers of oxygen atoms and hydroxyl groups with magnesium in octahedral sites and silicon in tetrahedral sites. The usual requirement that slip planes avoid cutting the strong $\mathrm{Si}-\mathrm{O}$ bonds is easily met (Figures $9 a$ and $9 b$ ) and does not strongly constrain the choice of slip planes. Perfects and dissociated $\langle a\rangle$ dislocations are found in the basal plane (at 700 and $400^{\circ} \mathrm{C}$, respectively). Dissociated $\langle c+a\rangle$ dislocations are observed in pyramidal 
planes at $400^{\circ} \mathrm{C}$, and prismatic glide is found at $400^{\circ} \mathrm{C}$. All these observations are compatible with the crystal structure (no Si-O bonds cut). We can raise the hypothesis that the core dislocations in phase $\mathrm{A}$ is spread (in the basal plane for $\langle a\rangle$ dislocations and in pyramidal planes for $\langle c+a\rangle$ dislocations). At $700^{\circ} \mathrm{C}$, this core spreading is too small to be observed by WBDF, but it strongly constrains the choice of the glide planes and slip systems. Larger stresses related to deformation at $400^{\circ} \mathrm{C}$ allow wide separation of the partial dislocations and reveal this core structure.
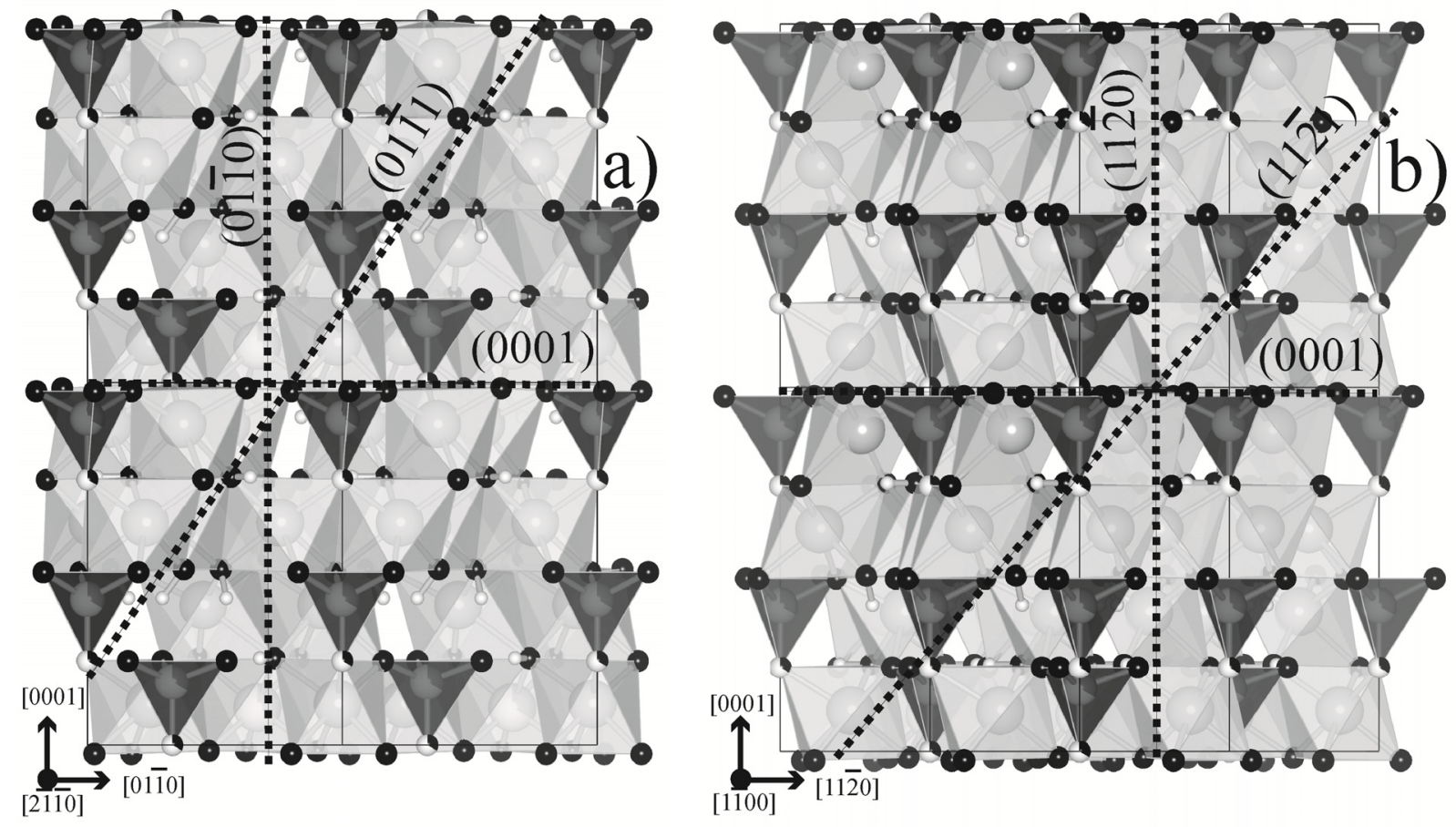

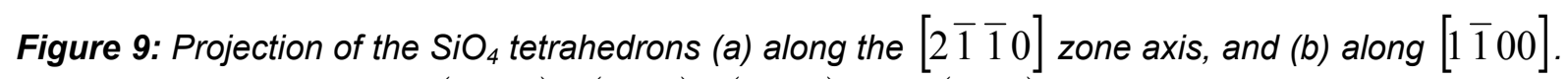
The trace of the (0001), (01 $\overline{1} 0),(11 \overline{2} 0),(01 \overline{1} 1)$ and $(11 \overline{2} 1)$ planes, are indicated by dashed black straight lines.

Furthermore, twinning in phase A has been evidenced. Figure 10 shows zone axis patterns of zone $A$ and zone $B$ (see figure 8). When we compare the experimental and simulated precession diffraction patterns in zone $A$ (fig. 10a and 10b), and proceed similarly in zone B (fig. 10c and 10d), as well as in zone A/B (fig. $10 \mathrm{e}$ and $10 \mathrm{f})$, we notice that some reticular planes are in common both in zone $\mathrm{A}$ and B (see table I). 
Table 1: List of the superimposed reciprocal directions in zone A and B.

\begin{tabular}{cc}
\hline $\mathbf{g}$ in zone A & Corresponding $\mathbf{g}$ in zone B \\
\hline $1 \overline{5} 40$ & $1 \overline{5} 40$ \\
$\overline{1} \overline{2} 36$ & $2 \overline{3} 1 \overline{6}$ \\
$\overline{2} 3 \overline{1} \overline{6} 6$ & $12 \overline{3} \overline{6}$ \\
$07 \overline{7} \overline{6}$ & $\overline{3} 8 \overline{5} 6$ \\
$3 \overline{8} 5 \overline{6}$ & $0 \overline{7} 76$ \\
$3 \overline{1} \overline{2} \overline{1} \overline{2}$ & $\overline{3} 1212$ \\
\hline
\end{tabular}

The twin law is obtained using the stereographic projections. We have superimposed the stereographic projections along the pole directions $\left[\begin{array}{l}3 \overline{1} \\ 2\end{array}\right]_{A}$ and $[\overline{3} 12 \overline{1}]_{B}$. These projections are then rotated along the similar poles in order to have $(1 \overline{5} 40)_{A}$ // $(1 \overline{5} 40)_{B}$. By analyzing the stereographic projection along the $[1 \overline{5} 40]$ invariant direction, we can note that the rotation angle which verifies the previous relations, is $180^{\circ}$ (see fig. 11). Consequently, the twin law corresponds to a rotation of $180^{\circ}$ around the $[1 \overline{5} 40]$ axis.

Moreover, the twin index $\Sigma$ is given by the following formula (Friedel, 1964):

$\Sigma=X / 2$ with $X=|u h+v k+w l|$ if $X$ is pair, otherwise $\Sigma=X$

where $u, v$ and $w$ are the indices of the twin axis (with three indices notation), and $h$, $k$ and $I$ are the indices of the plane perpendicular to the twin axis (three indices notation). Here, $u=-1, v=-3, w=0, h=1, k=-5$ and $I=0$, consequently we can deduce that $\Sigma=7$. Furthermore, the number of spots which match with zone $A$ and $B$ (see fig. 10f), corresponds to $\Sigma-1$. Here, we find 6 of them; so we obtain $\Sigma=7$ again. The twin observed in figure 7 is consequently a reticular merohedral twin with an index of 7 obtained with a $180^{\circ}$ rotation around the $[1 \overline{5} 40]$ axis. It is unusual to observe index twins higher than 5. However, some examples are available as, for example, for chalcocite where the [7413] twin axis creates a twin index of $\Sigma=19$ (Nespolo et al., 2006). Furthermore, a twin index of 7 , for a hexagonal structure with a cla ratio of 1.22, has already been mentioned by Grimmer \& Kunze (2004). Moreover, the microstructure of those twins (large domains, no dislocation involved) suggests that they result from growth rather than from plastic deformation. 

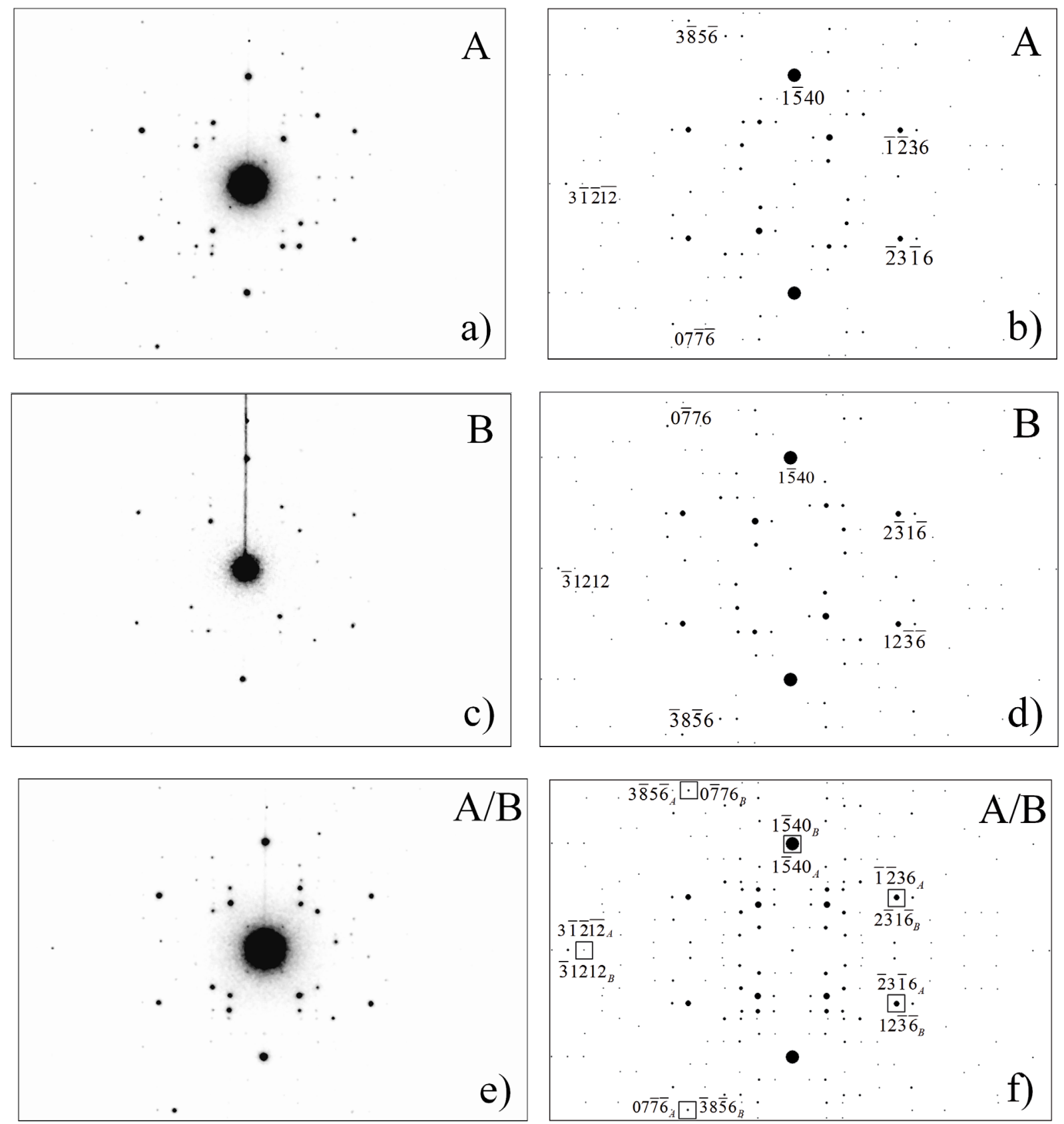

Figure 10: Precession Electron diffraction patterns: (a) experimental pattern in zone $A$; (b) simulated

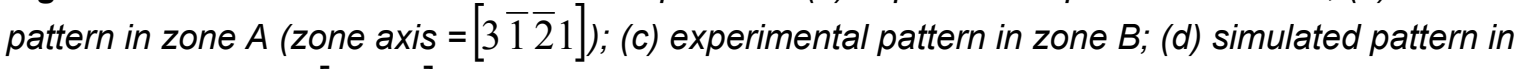
zone $B$ (zone axis $=\left[\begin{array}{l}3 \\ 1\end{array} 2 \overline{1}\right]$ ); (e) experimental pattern in zone $A / B$; (f) simulated pattern in zone $A / B$ with coincidence spots annotated by black empty squares. 


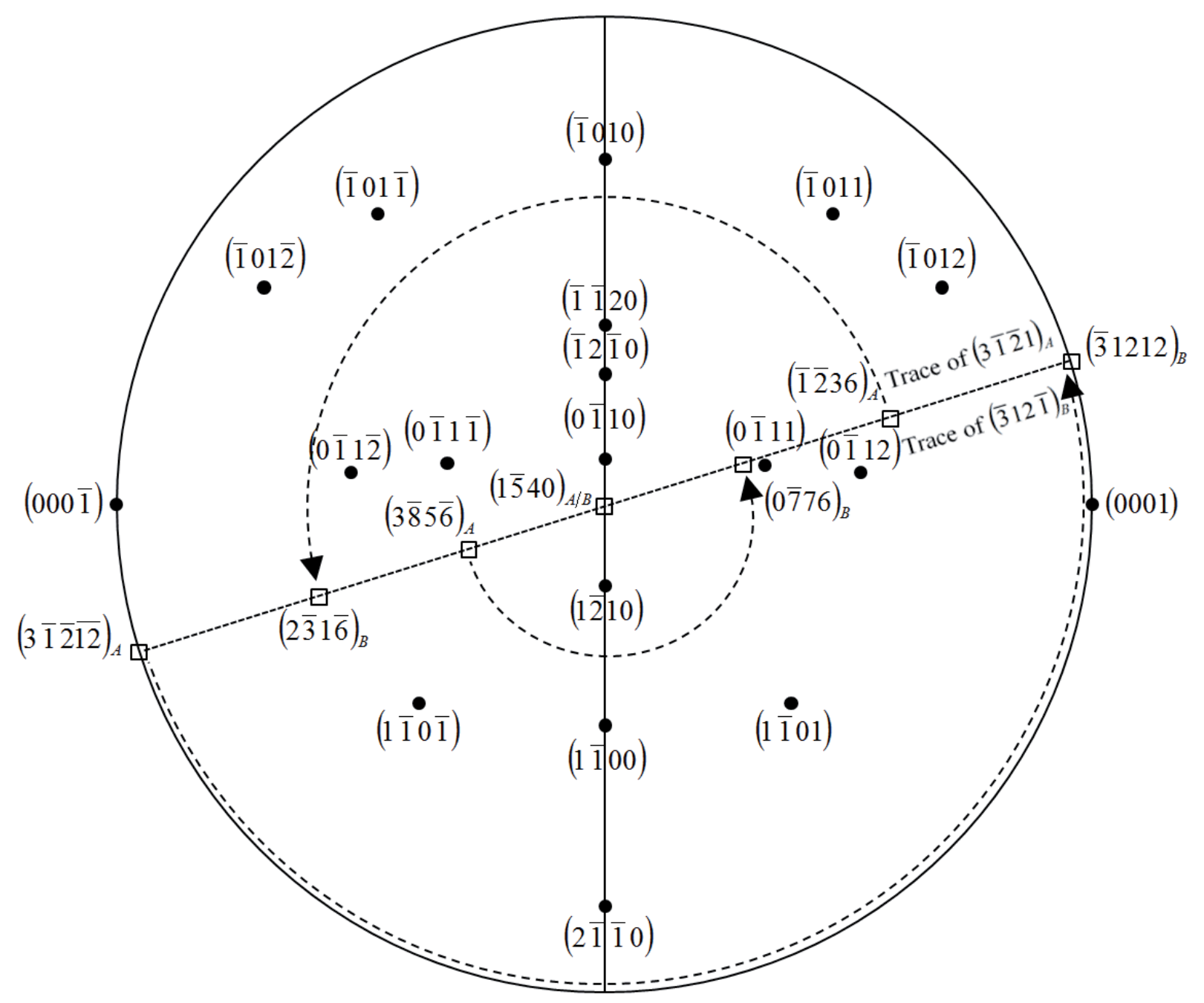

Figure 11: Stereographic projection along the $[1 \overline{5} 40]$ invariant pole. The trace of the perpendicular planes to the zone axes of figure 10 , for zone $A$ (i.e. $\left.(3 \overline{1} \overline{2} 1)_{A}\right)$ and zone $B$ (i.e. $(\overline{3} 12 \overline{1})_{B}$ ), are indicated by a dashed straight line. The reticular planes which coincide with zone $A$ and zone $B$ are appointed by empty black squares. The rotations along the $[1 \overline{5} 40]$ invariant pole verify that the $(3 \overline{1} \overline{2} \overline{12})_{A}$ reticular plane coincides with the $(\overline{3} 1212)_{B}$ one; the $(\overline{1} \overline{2} 36)_{A}$ reticular plane coincides with the $(2 \overline{3} 1 \overline{6})_{B}$ one; and the $(3 \overline{8} 5 \overline{6})_{A}$ reticular plane coincides with the $(0 \overline{7} 76)_{B}$ one. The twin law is consequently a rotation of $180^{\circ}$ along the $[1 \overline{5} 40]$ direction.

To recapitulate, two specimens of phase $A$, from an assemblage containing enstatite, were synthesized using a multianvil press at $900^{\circ} \mathrm{C}$ and $11 \mathrm{GPa}$. Then, a sample is deformed at the same pressure at $700^{\circ} \mathrm{C}$, and another sample is deformed at the same pressure, at $400^{\circ} \mathrm{C}$. Under these conditions, both phases are significantly deformed by dislocations. Dislocations with $\langle a\rangle$ and $\langle c+a\rangle$ Burgers vectors have been identified. No $\langle c\rangle$ type dislocations could be characterized precisely, but we cannot exclude their occurrence. The $\langle a\rangle$ dislocations glide in the 
basal plane where they can be observed widely dissociated at $400^{\circ} \mathrm{C}$. The same kind of conclusion holds for $\langle c+a\rangle$ dislocations in pyramidal planes. Dislocations gliding in $\{11 \overline{2} 0\}$ prismatic planes have not been identified.

Furthermore, we have characterized a reticular merohedral twin with a twin index of 7 , defined by a rotation of $180^{\circ}$ around the $[1 \overline{5} 40]$ direction.

\section{Acknowledgements:}

This study was supported by the ANR project SUBDEF grant $n^{\circ}$ ANR-08-BLAN-0192. The TEM national facility in Lille is supported by the CNRS (INSU) and the Conseil Régional du Nord - Pas de Calais, France.

\section{References}

Cordier, P. \& Rubie, D.C. (2001): Plastic deformation of minerals under extreme pressure using a multianvil apparatus. Mater. Sci. Eng. A, 309-310, 38-43.

Durinck, J., Legris, A., Cordier, P. (2005): Pressure sensitivity of olivine slip systems: first-principle calculations of generalised stacking faults. Phys. Chem. Minerals, 32, 646-654.

Friedel, G. (1964): Leçon de cristallographie. A. Blanchard éd., Paris, 250 p.

Grimmer, H. \& Kunze, K. (2004): Twinning by reticular pseudo-merohedry in trigonal, tetragonal and hexagonal crystals. Acta Cryst. A, 60, 220-232.

Ham, R.K. (1961): The determination of dislocation densities in thin films. Phil. Mag., 6, 1183-1184.

Heggen, M., Houben, L., Feuerbacher, F. (2010): Plastic-deformation mechanism in complex solids, Nature Materials, 9, 332-336.

Hilairet, N. \& Reynard, B. (2009): Stability and dynamics of serpentinite layer in subduction zone. Tectonophysics, 465, 24-29.

Hilairet, N., Reynard, B., Wang, Y.B., Daniel, I., Merkel, S., Nishiyama, N., Petitgirard, S. (2007): High-pressure creep of serpentine, interseismic deformation, and initiation of subduction. Science, 318, 1910-1913.

Horiuchi, H., Morimoto, N., Yamamoto, K., Akimoto, S.I. (1979): Crystal-structure of $2 \mathrm{Mg}_{2} \mathrm{SiO}_{4} \cdot 3 \mathrm{Mg}(\mathrm{OH})_{2}$, a new high-pressure structure type. Am. Miner., 64, 593598. 
Ishida, Y., Ishida, H., Kohra, K., Ichinose, H. (1980): Determination of the Burgers vector of a dislocation by weak-beam imaging in a HVEM. Phil. Mag. A, 42 , 453-462.

Komabayashi, T. \& Omori, S. (2006): Internally consistent thermodynamic data set for dense hydrous magnesium silicates up to $35 \mathrm{GPa}, 1600$ degrees $\mathrm{C}$ : Implications for water circulation in the Earth's deep mantle. Phys. Earth Planet. Inter., 156, 89-107.

Komabayashi, T., Omori, S., Maruyama, S. (2004): Petrogenetic grid in the system MgO- $\mathrm{SiO}_{2}-\mathrm{H}_{2} \mathrm{O}$ up to $30 \mathrm{GPa}, 1600$ degrees C: Applications to hydrous peridotite subducting into the Earth's deep interior. J. Geophys. Res., 109, B03206.

Komabayashi, T., Omori, S., Maruyama, S. (2005): Experimental and theoretical study of stability of dense hydrous magnesium silicates in the deep upper mantle. Phys. Earth Planet. Inter., 153, 191-209.

Meade, C. \& Jeanloz, R. (1991): Deep-focus earthquakes and recycling of water into the earth's mantle. Science, 252, 68-72.

Meltzman, H., Kauffman, Y., Tangadurai, P., Drozdov, M., Baram, M., Brandon, D., Kaplan, W.D. (2009): An experimental method for calibration of the plasmon mean free path. J. Microsc., 236, 165-173.

Metsue, A., Carrez, P., Denoual, C., Mainprice, D., Cordier, P. (2010): Plastic deformation of wadsleyite: IV Dislocation core modelling based on the PeierlsNabarro-Galerkin model. Acta Mater., 58, 1467-1478.

Miyajima, N. \& Walte, N. (2009): Burgers vector determination in deformed perovskite and post-perovskite of $\mathrm{CalrO}_{3}$ using thickness fringes in weak-beam dark-field images, Ultramicroscopy, 109, 683-692.

Nespolo, M. \& Ferraris, G. (2006): The derivation of twin laws in non-merohedric twins. Application to the analysis of hybrid twins. Acta Cryst. A, 62, 336-349.

Omori, S., Komabayashi, T., Maruyama, S. (2004): Dehydration and earthquakes in the subducting slab: empirical link in intermediate and deep seismic zones. Phys. Earth Planet. Inter., 146, 297-311.

Ringwood, A.E. \& Major, A. (1967): High pressure reconnaissance investigations in system $\mathrm{Mg}_{2} \mathrm{SiO}_{4}-\mathrm{MgO}-\mathrm{H}_{2} \mathrm{O}$. Earth Planet. Sci. Lett., 2, 130-133. 
Schmidt, M.W. \& Poli, S. (1998): Experimentally based water budgets for dehydrating slabs and consequences for arc magma generation. Earth Planet. Sci. Lett., 163, 361-379.

Thurel, E. \& Cordier, P. (2003): Plastic deformation of wadsleyite: I. High-pressure deformation in compression. Phys. Chem. Minerals, 30, 256-266.

Ulmer, P. \& Trommsdorff, V. (1995): Serpentine stability to mantle depths and subduction-related magmatism. Science, 268, 858-861.

Vincent, R. \& Midgley, P.A. (1994): Double conical beam-rocking system for measurement of integrated electron diffraction intensities. Ultramicroscopy, 53, 271-282.

Yamasaki, T. \& Seno, T. (2003): Double seismic zone and dehydration embrittlement of the subducting slab. J. Geophys. Res., 108, 2212. 